\title{
The Research on Support and Reinforcement of Deep Foundation Pit
}

\author{
Liqin Ai
}

\author{
Nanchang Institute of Science \& Technology
}

Keywords: Deep foundation pit; Support; Reinforcement; Optimizing

\begin{abstract}
The deep foundation pit engineering is a complex system engineering. The supporting structure must be safe and reliable and the costs must be economical and practical in its design process. For coordinating the relationship between them, the optimization design of deep foundation pit supporting engineering is born. As the optimization of deep foundation pit supporting engineering has many difficulties, such as (1) continuous variables and discrete variables coexist in the design variables, variables are numerous, variable combination are large; (2) as the optimization goal and design variables are complex, each design variable on the sensitivity of the optimization goal is not consistent, set up reasonable explicit expression is more each design variable on the sensitivity of the optimization goal is not consistent, establish reasonable explicit expression is difficult, so the traditional optimization algorithm in the face of complex optimization problem of deep foundation pits are often powerless, therefore, to find a reasonable and feasible optimization algorithm is the key. This paper analyzes the reason of foundation pit supporting instability, optimizes the supporting design and puts forward the proposals of corresponding reinforcement.
\end{abstract}

\section{Introduction}

In recent years, with the construction of tall and super-tall building in our country, appeared a spate of deep foundation pit engineering, because of the complexity of the geological, variability of stress state and the diversity of structure, especially in Shanghai, Guangzhou and other big city with slope soft soil thickness is more apparent, deep foundation pit supporting project design and construction of technical problems increasingly complex diverse, due to improper scheme selection, design thoughtless and construction management does not reach the designated position, the accident of deep foundation engineering frequently happen in recent years. To a degree, deep foundation pit supporting engineering is a complex system engineering, it involves almost all aspects of the rock and soil mechanics and engineering, such as soil mechanics, engineering geology, hydrogeology, structural mechanics, and supervision, monitoring and construction method, etc. As a result, there are more uncertainty factors influencing the stability of foundation pit, this leads to the foundation pit engineering accident rate high, especially in southeast coastal open cities, large accident of foundation pit engineering is about a third of the total number of foundation pit in some cities. Once support failure, the consequences would be horrific, not only delay the construction period and economic damage, more importantly, also has the bad influence which cannot be underestimated on the surrounding buildings and urban lifeline engineering, this even endanger personal safety. So urgently need a supporting design scheme, so this article will analysis the principle of deep foundation pit support design and optimization and the reinforcement of the support.

\section{The Design Principle of Deep Foundation Pit Supporting Structure}

Supporting structure should follow the principle of safety first, economy second, which should be under the premise of the normal use, the safe construction of supporting structure as much as possible to save investment. At the same time, it should also follow the following principles when design:

(1) The foundation pit supporting structure should be expressed as a design expression of partial coefficient of the limit state (ultimate limit state and servicing limit state).

(2) The foundation pit supporting design should choose corresponding sidewall safety level and 
importance coefficient which based on supporting structure damage, soil instability or excessive deformation with the influence degree of foundation pit surrounding environment and the underground structure facilities.

(3) Supporting structure design should consider its structure deformation and the horizontal and vertical deformation influence of the change of groundwater level on the surrounding environment, security level for level 1 and deformation of surrounding environment have qualified requirements of secondary building foundation pit side wall, it should be based on the importance of the surrounding environment, such as factor like the adaptive capacity of the deformation and the nature of soil to determine the horizontal deformation value of the supporting structure.

(4) If the field in groundwater, it should be according to the site and the surrounding area of the engineering geologic condition, hydrology geological condition, the surrounding environment situation and the supporting structure and basic form factor, determine groundwater control method. If surface water around on the bottom flow, passage or underground conduit leakage, it should take protective measures on foundation pit.

(5) If the field in groundwater, it should be according to the site and the surrounding area of the engineering geologic condition, hydrology geological condition, the surrounding environment situation and the supporting structure and basic form factor, determine groundwater control method. If surface water around on the bottom flow, passage or underground conduit leakage, it should take protective measures on foundation pit.

(6) When conditions permit, foundation pit should be excavated in partial or whole, the slope degrees should meet the requirements of its stability.

\section{Optimization Design of Deep Foundation Pit Support}

Simple arc-slice analysis method is one of the most commonly used methods in overall stability analysis of soil nailing. In the process of analysis, assuming that sliding surface is circular, the soil is just shaping material, regardless of the article on the mutual force and moment. This paper studies soil nailing method for calculating the overall stability of the middle-earth layered heterogeneous.

1. Basic assumptions

(1) The most dangerous sliding surface is slope circular arc, through soil nail wall ground Angle point A;

(2) The center of the most dangerous slip surface is located above the soil nailing wall, that is located above the BC, as shown in Fig. 1.

2. The establishment of the model

(1)The coordinate system of soil nail stability analysis

Use circular arc sliding simple arc-slice analysis method overall stability calculation of soil nailing wall, built the rectangular coordinate system at first, take the bottom of the foundation pit slope foot A point for coordinate origin, foundation pit depth direction for the $y$ axis, A direction perpendicular to the deep foundation pit for the $\mathrm{x}$ axis.

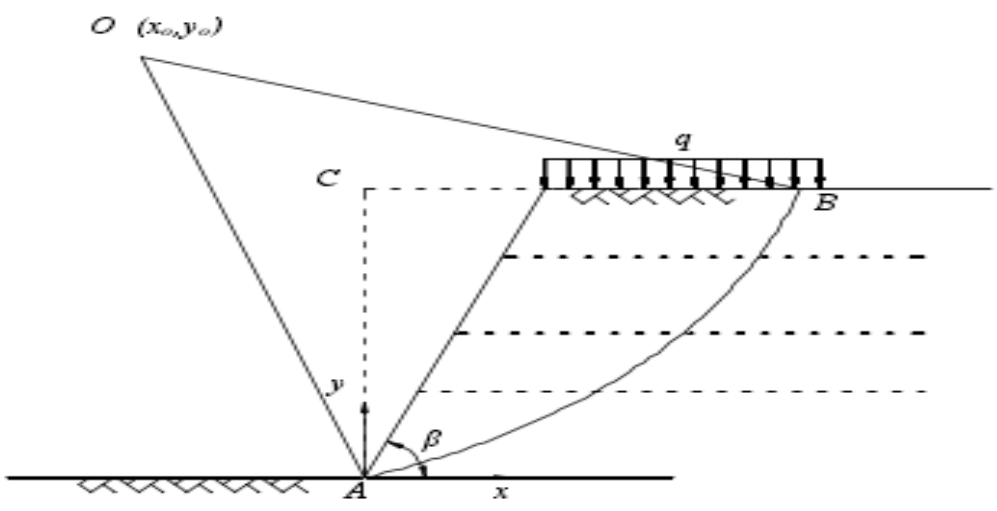

Figure 1. The stability analysis coordinate system 
(2) The sliding surface circular arc radius

As shown in Fig. 1, the center coordinates of the circular sliding surface is $\mathrm{O}\left(\mathrm{x}_{0}, \mathrm{y}_{0}\right)$, the radius of the circular is $\mathrm{R}$, the depth of foundation pit is $\mathrm{H}$, than the equation of sliding surface:

$\mathrm{x}_{0}^{2}+y_{0}^{2}=R^{2}$

The point of intersection between the sliding surface and the ground is B with the coordinate of $\left(\mathrm{x}_{B}, \mathrm{H}\right)$

$\mathrm{x}_{B}=\sqrt{R^{2}-\left(y_{0}-H\right)}+x_{0}$

According to the principle of simple strip method, sliding surface A and B are divided into $\mathrm{n}$ parts, and the width of the circular arc and the transverse coordinates of each section of the arc are respectively:

$$
\begin{aligned}
& \mathrm{b}=\frac{x_{B}}{n} \\
& \mathrm{x}_{i}=\frac{b}{2}+(n-1) b
\end{aligned}
$$

Supporting structure

$$
\text { reinforcement }
$$

for

anchor

$\operatorname{rod} \mathrm{F}=7.85^{*} \sum_{i=1}^{N} \frac{\pi}{4} d_{a}^{2} \cdot L_{i} \cdot \frac{L_{g}}{S_{h}} \cdot C_{a}+\sum_{\mathrm{i}=1}^{N} \mathrm{~L}_{i} \cdot \frac{L_{g}}{S_{h}} \cdot C_{m}+\left(A_{s} \cdot C_{s}+\frac{\pi}{4} d_{p}^{2} C_{c t}\right) \cdot \frac{L_{g}}{S_{h}} \cdot\left(H+h_{d}\right)$

2) Support structure is internal support

$$
\mathrm{F}=\left(\mathrm{A}_{\mathrm{s}} \cdot C_{s}+\frac{\pi}{4} d_{p}^{2} \cdot C_{c t}\right) \cdot \frac{L_{g}}{S_{h}} \cdot\left(H+h_{d}\right)
$$

In which, $\mathrm{N}$ is layer of anchor bolt; $\mathrm{L}_{\mathrm{i}}$ is the length of the anchor bolts of each layer; $\mathrm{A}_{\mathrm{s}}$ is reinforcement area; $\mathrm{C}_{\mathrm{s}}$ Row per $\mathrm{kg}$ cost of the piles and underground continuous wall reinforcement; $\mathrm{d}_{p}$ is pile diameter and wall thickness; $\mathrm{C}_{\mathrm{ct}}$ is cost of per cubic meter of concrete.

\section{Deep Foundation Pit Supporting Structure Characteristics and Strengthening Analysis}

\section{Deep mixing cement-soil enclosure wall}

Deep mixing cement-soil enclosure wall is that with deep mixer on the soil and input water mud of forced mixing and form a continuous cement-soil column reinforced retaining wall. This enclosure wall which uses its own weight and stiffness for soil retaining and seepage control belongs to gravity retaining wall, it has a dual role. Cement-soil enclosure wall in which a pit without support is advantageous for the mechanized earth-moving quickly, have the generally economic advantages of double function of cover soil and water. The downside is that it is not easily used in deep foundation pit, the deep should not be commonly more than $6 \mathrm{~m}$, and displacement is relatively large, especially in large length of foundation pit. When in large length of foundation pit it can take pier and arch in the middle or other measures to limit the excessive displacement, the second is the thickness is enough big, red line position and the surrounding environment have condition to do, and it should pay attention to prevent affect the surrounding environment when the cement mixing pile construction.

2. Reinforced concrete sheet pile

Reinforced concrete sheet pile is a traditional supporting structure enclosure wall, the cross section takes tongue-and-groove, no longer pull out after using, permanent in the foundation soil. Cross section has the definite thickness and rigidity, and can limit deformation. It is less applied in the construction, only used for construction of steel sheet pile which is difficult to pull out after location and some special cases. 


\section{Steel cross baffle}

Steel cross baffle enclosure wall plate is also called pile support structure. It is composed of thick stick steel pile $(\mathrm{H})$ and horizontal baffle (also called liner plate), and combined with like boxing and support to form a supporting system. Pile from the I-beam or h-beam in a certain distance while constructing, and set up cross baffle while digging. After construction, pull out the I-beam or H-beam pile, and recycle horizontal baffle as much as possible under the condition of safety permits.

4. SMW (stiffness soil-cement mixing pile)

SMW is called in Japan, and also called stiffness soil-cement mixing pile method. Insert h-beam steel in the cement mixing pile, make it to be the enclosure wall which has two functions of stress and permeability. If the deep pit is big, add supporting structure.

\section{Conclusion}

To achieve the above effect, supporting structure shall be meet the requirements in the aspects of strength, stability and deformation. If the strength or stability is not enough, retaining wall will be damaged, support will be bent, the pit will uplift or piping, these will cause damage of retaining structure and foundation construction, even endanger underground environment. For different regions, each project is different in the indicators of soil distribution and soil, and the geological condition is complex, these have increased the difficulty of the design and construction of foundation pit. So it should be according to the geological characteristics of specific projects and the conditions of the local construction, choose the safe and economic foundation pit supporting scheme. There are many kinds of technology of construction deep foundation pit which are still in development, with the continuous development of the design theory and construction technology, there will be a large number of new method of foundation pit supporting. Only master the principle of foundation pit supporting, the construction methods and the suitable soil, that will be according to the specific condition of different sites in the actual design, flexible adopts the method of foundation pit supporting.

\section{References}

[1] Xiong Q. Construction Technology of Single-ring Reinforced Concrete Beam Support of Deep Foundation Pit [J]. Construction Technology, 2001.

[2] Lu R L, Jiang Q H. Reinforcement Scheme and Numerical Simulation for Sequential Excavation of the Deep Foundation Pit [J]. Applied Mechanics \& Materials, 2012, 204-208:359-365.

[3] Hu X E. Reinforcement Design and Analysis of Deep Foundation Pit [J]. Fujian Construction Science \& Technology, 2009.

[4] Zhan W. The use of reinforced cement soil piles and anchors in a large ultra-deep foundation pit support [J]. Fujian Architecture \& Construction, 2012.

[5] Xiang-Fan L I, Yin J, Liu Y C, et al. Design of Internal Support of Reinforcement Loop Truss in Super-large Deep Foundation Pit [J]. Construction Technology, 2006.

[6] Chen P. The green dismantling technology of reinforced concrete supporting beam in deep foundation pit [J]. Fujian Architecture \& Construction, 2013.

[7] Du Y. Discuss the Supporting Reinforcement Construction Technology of Deep Foundation Pit [J]. Urbanism \& Architecture, 2013.

[8] Zhang W. Deep foundation pit supporting reinforcement of Bi Gui Yuan Building \# 6[J]. Fujian Architecture \& Construction, 2009.

[9] Jin J C. Rapid removal technology of internal reinforced concrete support system in deep 
foundation pit [J]. Shanxi Architecture, 2009.

[10] Wang H J, Jing-Yu L I. Reinforcement Design of High Voltage Transmission Tower Foundation Near Deep Foundation Pit [J]. Construction \& Design for Engineering, 2015, 18(6).

[11] Yang S, Cao Y, Sun H. Analysis of grouting reinforcement of marine silt formation deep and large foundation pit project[C]// Remote Sensing, Environment and Transportation Engineering (RSETE), 2011 International Conference on. IEEE, 2011:2900-2903.

[12] She H Y, Zhu Z D. Reinforcement Scheme Optimization for Passive Zone of Deep Foundation Pit in Sea Section of Gongbei Tunnel[J]. Journal of Water Resources \& Architectural Engineering, 2013. 